\title{
A Study on the Visual Dynamic Design of New Media Advertising
}

\author{
Xuying Wang \\ Dept.of Indvstrial Design \\ Pukyong National University \\ Busan, Republic of Korea
}

\author{
Jang Chung Gun \\ Dept.of Visual Design \\ Pukyong National University \\ Busan, Republic of Korea
}

\begin{abstract}
As the informatization level increases in China, the application of the new media in the social development and civil life also have increased. The emergence of new media provides chances for the development of advertisement design. With the spreading of advertisements, the creativity and visual presentation of the advertisements have new mode, which fully makes up for the disadvantages of traditional print media advertising. This paper described the visual dynamic design first, analyzed the design methods of the visual dynamic design in the new media advertising, studied the main points of the visual dynamic design of new media advertising and finally analyzed the application value of the visual dynamic design of new media advertising. It is hoped this study would have its reference significance.
\end{abstract}

Keywords-new media; advertising creativity; visual dynamic design; visual presentation

\section{INTRODUCTION}

Under the background of market economy, in order to improve its market competitiveness, enterprises must build up its brand image and fully use advertising to explore the market. Advertising should not only be creative and unique in plot, but also be presented very fully, so as to provide special feelings for the consumers and promote consumption behavior. It can be seen that the visual effect of the advertisements is very important. Currently, China has entered into information age. The new media including internet and mobile TV is very common, which changed the reading habits of the consumers. Nowadays, there are many advertisements in the enterprise market. In order to attract the attention of the consumers, the advertising designers have to fully use the visual dynamic design to generate the visual effect of dynamics and integration.

\section{SUMMARY OF VISUAL DYNAMIC DESIGN}

In the past, the print media were the main communication media in China. Advertising visual communication design focused on the print ads. As time goes on, image and video became the communication media also. The development of digital information technology took the ads to the internet. There are many website ads and multimedia ads. People's recognition of the new media advertising design still remains in the technology aspect of the new media. They don't pay much attention on the advertising visual communication design. Actually, as for the advertising visual forms, the print ads convey the static status, two-dimension vision, while new media convey dynamic status and four-dimension vision. Advertising visual dynamic design of the new media refers to a kind of visual communication design starting with the concept of dynamic visual concept, which fully uses the imaging technology, sensing technology, photoelectric technology, animation technology and computer virtual technology, combining dynamic media and static media. Dynamics not only includes the visual elements, but also communication media, which fully presents two meanings of visual dynamic design. Broadly speaking, the communication activity of new media ads is in a dynamic status. Its communication has high interactivity. Narrowly speaking, the basic visual elements of the new media ads are dynamic, including light, image and animation.

\section{The Visual Dynamic Design Methods of the NEW MEDIA}

First of all, the interactive dynamic visual design. Advertisements, fundamentally is the communication between the ads designer and the audience. The communication of the new media ads with the audience is realized through various sensory ways to make sure that brains, hands and hearts are dynamic. Accordingly, the audience can have general interactive effects from acceptance, recognition and feedback. New media ads can make the consumers integrate into the ads. In the constant interaction, they can have various sensory experience. Interactive visual dynamic design can be divided into the following ways according to the interactions. First of all, the dynamic sensors, which can be commonly seen, generate visual dynamic effect using the interaction with the consumers. Namely, setting chips into the billboards. Ads will have action as the people operate the billboards. Secondly, scene detection provides real scene for the consumers, so that the products can be presented the the audience in the corresponding scene. Some of the ads designers use the virtual scene technology, so that the consumers can feel the products. Thirdly, games have very strong interactivity. The audience can control the games so as to generate dynamic effect. According to its relationship with the internet, it can be divided into online game ads and offline game ads.

In the next place, the integration among media. Under the background of new media, integration and application 
various media can effectively improve the efficiency of the communication. It can not only broaden the coverage of the target audience, but also adapt to the complicated media environment. Full integration of the new media technology and the traditional media ads can realize the digital upgrade of the traditional media. Combining several new media which have the feeling of experience and dynamics and integrating their advantages together can not only bring into play their merits, but also make up for the blank space of a single media. It not only broadens the communication coverage of the ads, but also improves the recognition of the brands and strengthens the information communication. Dynamic light box ads and dynamic cabinet ads are the examples.

Finally. Full application of various technologies. In the ads design, electricity, light and sound technology are fully used, while creative concept of advertising and appeal strategy are combined together, so dynamic presentation with multi-sensory experience can be realized. This makes up for the shortcomings of the interactive and integrative advertising forms. Besides, application of new media technology breaks the routine of the dynamic presentation and reach the momentary visual attraction.

\section{A. The Main Points in the Visual Dynamic Design of New Media Ads}

First of all. Design the suggested signs of the interaction. Nowadays, people can reach a lot of ads in the new media environment. These ads differ in quality. Because the number of ads which the audience can accept is limited, if the audience accept too many ads, they will automatically conduct a self-protecting mode. Namely, they will filter the irreverent information and obtain demanding or interested information. Therefore, creative signs, sharp color and dynamic ads won't be filtered. Because of the interactivity of the new media, the audience will not only accept the information, but also take part in the information releasing and make feedback with the advertising media and the advertisers mutually. Accordingly, when designing the interaction part, make sure that the interaction is easy and there is no complication operation and that signs suggesting interaction should be well designed. The signs in the ads should be remarkable and relevant to the ads. The signs should be different before and after operation.

Secondly, design the steps of dynamic presentation. Firstly, it should drag the attention of the consumers. Through exciting pictures or dynamic scenes, it should drag consumers' attention to the ads plot. Next, if the consumers are willing to continue watching the ads, it should lead them to take part in the interaction in the ads actively and make them integrate into the ads plot. Lastly, if the consumer can have good experience feelings, advertising information can be introduced naturally.

Next, design the dynamic scene. People's consumption develops from quantity consumption, quality consumption to emotional consumption. If the consumers realize their emotional consumption, the economic value will be greatly improved. The recognition, acceptance and purchase of a product is an emotional process for a consumer, so advertising creativity should satisfy the emotional demand of the consumers. In the past, consumers watch ads passively. New media's visual dynamic ads present dynamic effect, build up emotional experience environment for the audience and excite the various senses of the consumers, so the consumers can accept the advertising information during the emotional experience process. Meanwhile, the commercial atmosphere of the ads is soften and consumers' purchase desire can be evoked.

Then, design the communication way of the advertising information. One is text messages. Although traditional print ads also have text, the texts in the new media ads are very different. There is no punctuation and the Kerning and row spacing also have rules. The absorptivity, speed, rhythm and readability are greatly paid attention to. The other is graphic information. Graphs can accurately express the information with very simple visual words, which are easy to generate association and to remember. Graphs have stronger expression ability than texts. In the advertising information design, dynamic graphs can be used to replace the text messages.

Lastly, the harmonious relationship between design and the carrier environment. The communication effect of the ads has very important relationship with the carriers. Same ads have different presentation ways in different new media carriers, so as to reach a harmonious relationship between design and the carrier environment. Take the mobile phone as an example. Mobile phones have a small screen and limited electricity, The information that can be presented is limited also. Therefore, when designing the ads for the mobile phones which are the carrier, it is necessary to make sure that the pictures and videos can adapt to the screen resolution, that the information it conveys is not very much, and that the video length is not very long.

\section{The Application VAlue of the Visual Dynamic DESIGN OF THE NEW MEDIA AdS}

First of all, audience's experience value. Nowadays, it has entered into a experiencing economy age. People hope that they can fulfill their emotional demand through experiencing something, so as to have some feelings. Experience economy provides experience situation for the consumers to realize high efficient communication of the advertising information. Under this environment, consumers are no longer the audience of the ads. They actively take part in the ads instead. Excellent ads can fulfill the curiosity of the audience and the demand of entertainment, aesthetics and study. They hope that ads can bring more value and experience to them. As for visual experience, under the real situation in which there are many ads and people sometimes choose to neglect ads, designers should make sure that the ads can bring very strong visual excitement to the consumers and make them feel different in visual experience. Visual dynamic design refers to the real visual experience brought to the audience by using technologies and making sure that the advertising pictures and situation in the real or virtual space can change very flexibly.

Then, in modern society, consumers tend to fulfill selfrealization and obtain excitement through leisure and 
entertainment like games. New media ads should fulfill the entertainment experience of the consumers, bring overall joy for the consumers, build up experience situation and bring the audience into the ads through virtual experience, high participation, humorous expression and three-dimensional communication in the visual dynamic design. The other one is technology experience.New media ads fully use the science technology. These ads are the combination of art and technology. Technology in the new media advertising design is very important element. New media advertising visual dynamic design cannot do without technology experience. Audience can generate joyful feelings when access to the optoelectronic technology, touch technology, computer network technology and virtual reality technology. The final one is emotional experience. In the new media advertising visual dynamic design, emotional experience is the most important part. It can fulfill consumers' demand mentally and emotionally, gives full play to consumers' various senses and let them associate and image in the ads, so as to reach psychological resonance and obtain real emotional experience.

Secondly, it is the value of advertising communication. Advertising design takes the communication maximization as the ultimate purpose. It influences the consumption consciousness and purchase behaviors. More importantly, audience's information reception and acceptance are different. Reception only remains on the surface, while acceptance is deep in mind. Consumers don't have requirements for the advertising ways or the communication methods. They pay more attention to the information, to see if the information is rich or convenient. In the fast-paced life, people need feeling of freshness, innovation consciousness and the application value of the ads. New media delete passive information that are imposed on the consumers. The consumers have more choices and it is easier for the audience to accept.

\section{CONCLUSION}

New media advertising visual dynamic design significantly changed the communication of the print media in the past and paid more attention to the force and charm provided by the product images. It can bring much richer visual feelings for the audience. The interactivity it has grasps people's mental demand, evokes emotional resonance and improves greatly the communication effect.

\section{REFERENCES}

[1] Xu Qian, A Study on the Visual Dynamic Design in the New Media Advertisements[J], Modern State-owned Enterprise Research, 2015(18):55.

[2] Tian Yi, Zhang Tianshuang, A Study on the Role of the Print Visual Design in the Dynamic Media Art[J]. Design,2015,(18):133-134.

[3] Ma Wenlian, Zhang Nanling, The Application and Study of the Visual Communication Design in the Dynamic Construction[J]. Art Technology, 2015(08):196-197.

[4] Liu Haiyan, The Application Value of the Visual Dynamic Design in the New Media Advertisements[J]. Journalistic front, 2015(12):58-59.

[5] Huang Rongmei, The Application and the Development Direction of the Dynamic Visual Communication Design in the Digital Media[J].
Journal of Sichuan Vocational and Technical College, 2015(02):164166.

[6] Huang Rongmei. The Dynamic Visual Sign Design in the Digital Media[J]. Journalistic front, 2015(04):16-17.

[7] Wang Jingjuan, Yanlv, The Dynamic Graphic Design in the Digital Media-Visual Creation of Film and Television Advertisement of Automobile Industry[J]. Decoration, 2013(07):90-91.

[8] Wang Jinfeng, A Study on the Development Trend of Visual Communication Design in the New Media Age[J]. Popular Literature, 2012(10):43-44. 